\title{
Comparative Analysis of Student's Live Online Learning Readiness During the Coronavirus (COVID- 19) Pandemic in the Higher Education Sector
}

\author{
Yunyi Zhu ${ }^{1, *}$, Jialin $\mathrm{Ma}^{2}$
}

\author{
${ }^{1}$ Jiangsu Tianyi High School \\ ${ }^{2}$ Qingdao No.58 High School Shangdong Province \\ *Corresponding author. Email: zyy040707@outlook.com
}

\begin{abstract}
In COVID-19, many countries face a critical situation in terms of the global economy and human activities, including education. The school closure affected many students around the world. In the early days of the outbreak, many of the countries facing the disaster of the epidemic-imposed school closures. This study explored several key factors in the research framework, such as learning motivation, learning preparation and self-efficacy of students participating in online learning during the COVID-19 epidemic. On the other hand, gender differences decreased during the coronavirus epidemic as students were forced to learn more actively, according to post facto testing. At the same time, students at the higher education level may have higher expectations for their academic achievement and differ significantly in their readiness for online learning.
\end{abstract}

Keywords: analysis, online-learning, challenges, opportunities

\section{INTRODUCTION}

After nearly two decades after SARS, a more destructive novel coronavirus, has spread around the world (Guan et al., 2020). The coronavirus outbreak resulted in over one million deaths, with more than 43 million people infected (WHO, 2020).

The virus has continued its momentum in global situation, affecting human social activities, especially in education. (Qiu, 2018). Many countries have implemented various policies to control the damage. These measures also affect the education sector, with schools forced to close (Stancati 2020; BBC, 2020; MOE, 2020; Education Bureau, 2020).

In response to the coronavirus outbreak, remote has to be the only solution for education under COVID-19 since offline class has been forced to shut down.

Online remote learning help student to continue to study and minimize the impact on students' academic progression. However, online learning also encounters several challenges. For many students, they do not have internet access (Zhang, 2020). For many teachers, they need to care about infrastructure's readiness. [1]
Also, in online learning situation, there are barely few discussions about differences in student perception in live online learning environments between students from different education levels and genders. Therefore, it is important to determine students' learning readiness for this mode and evaluate their difference between different groups of students during the pandemic.

For major research questions:

1. What underlying factors contribute to students' live online learning readiness during the coronavirus pandemic in the higher

education sector?

2. Is student readiness for live online learning affected by gender?

3. Is student readiness for live online learning affected by the education levels of students' degrees, including sub-degree (SD), undergraduate (UG), and postgraduate (PG) degrees?

4. What core factors contribute to differences in student readiness for live online learning between genders and education levels? 


\section{THEORETICAL DEVELOPMENT}

\subsection{Online teaching and learning:}

Although online learning has been used for several years, its impact remains unsatisfactory, because many teachers refused to use online teaching tools since online teachings is not traditional teaching method. [2]

On the other hand, students are not used to use online learning platform. Technology and communication competencies are the keys to enhance student's retention and satisfaction, but students' participations are largely affected by their own motivations and presences (Law et al., 2019; Widjaja, 2017). Some learning activities are introduced to enhance students' presence (Rensburg, 2018; Rohrbach, 2014).

Educational institutes are forced to shift their teaching methods towards more flexible to enhance students' learning, but the most important challenge is that students do not participate in class, which means the successful implementations of this change is decide on whether students are motivated to attend online learning. [3]

\subsection{Live online learning readiness}

Live online learning refers to the teaching activities carried out through live online broadcasting. Teachers must post materials on the learning platform in advance and deliver them in real time, including lectures and tutorials, giving feedback on students' questions and allowing students to discuss them in class. However, students can participate in live classes anywhere, so teachers find it impossible to monitor or control whether students are ready for live online learning environments remains unknown. Student readiness for online learning is considered one of the prerequisites for an effective learning process and educational achievement. Unlike traditional face-to-face classroom teaching, distance learning does not guarantee student attendance, so it is difficult to determine the concentration of students studying online. Students' readiness for online real-time learning has a significant impact on students' willingness to participate in class and the quality of online real-time learning. Therefore, it is important to investigate the core factors that influence students' preparation for online real-time learning.[4]

\subsection{Self-directed learning (SDL)}

Since 1916, self-directed learning has been defined and derived from the principles of adult education. It is believed that all people are free to develop and grow. The idea of education is that teachers are facilitators. Therefore, it is inappropriate to hinder or control the learning process. Knowles(1975) proposed that autonomous learning is a process in which students take the initiative to diagnose their own learning needs, set their own learning goals, appropriately identify and implement learning strategies, and finally evaluate their own learning results. Gengetal.(2019) proposes that autonomous learning emphasizes students' initiative, such as setting goals and making choices.[5]

\subsection{Online communication self-efficacy (OCS)}

Self-efficacy in online communication refers to students' ability to build personal and purposeful interpersonal relationships -- including the ability to form effective communication in group discussions (Alqurashi, 2016). In the past few decades, advances in information technology have facilitated the development of online communication. Online communication is becoming more and more important to students because it helps students achieve their goals effectively. Ansari and Khan (2020) and Li et al. (2014) argue that online communication contributes to collaborative learning, satisfies psychological gratification needs, encourages the social construction of knowledge, and contributes to the adoption of critical thinking skills.[6]

\subsection{Technology readiness $(T R)$}

Parasuraman (2000) proposes that technological readiness is "the tendency of people to embrace and use new technologies in their home life and work in order to achieve their goals. It has been identified as a key factor in strengthening behavioral will to high-tech services or products. Research on the impact of technical preparation on students' behavioral intention for online learning needs (Badia et al., 2014; Shirahada et al., 2019). Indeed, innovation and optimism are important for technological readiness, and insecurity and discomfort often hinder users' technological readiness.

\subsection{Learning control $(L C)$}

Learner control refers to enabling individual learners to judge the number of selected learning instances, arranged learning task sequences, structures, practices and learning sessions according to their own personal cognitive needs (Chang \& Ho, 2009; Chen \& Yen, 2019). The design and implementation of online learning needs to be consistent with students' preferences to make students more satisfied with their responses to online learning programs, so that this positive learning attitude improves participation in the learning task itself (Orvis et al., 2010).[7]

\subsection{Motivation learning $(M L)$}

Motivation is one of the most important factors for the success of today's students. However, Fredman(2014) and Lau and $\mathrm{Ne}(2015)$ point out that the changes of students' actual learning motivation attributes have not been fully studied. Motivational theorists emphasize the 
contributions of environment, socialization, and personal beliefs (Hufton et al., 2003; Oqvist \& Malmstrom, 2016). In doing so, a learning environment generates encouragement: students are highly motivated to educate and have a positive sense of well-being about their learning.

Motivation is one of the important factors for the success of many students' learning activities.[8]

\section{METHODOLOGY}

\subsection{Research framework}

the learning readiness model generalized from Phan and Dang (2017) and Hung et al. (2010) was used. This research framework contains five key factors: technology readiness, self-directed learning, learner control, motivation for learning, and online communication selfefficacy. This research validates the underlying factors of the proposed hypothetical model in determining student's readiness for online learning.

\subsection{Online learning tools}

Higher education institutions in Hong Kong, Macao and several Chinese cities participated in the study. For an online learning environment, we recruit faculty from various schools to teach online. To facilitate online teaching between Mainland students and teachers in Hong Kong, a new infrastructure with higher bandwidth capacity has been built using a secure virtual private network (VPN) connection. The VPN gateway is arranged to connect directly to the learning tool to reduce the impact of possible student connection problems.[9]

\subsection{Survey design}

The survey consists of three parts. The first part is a brief overview of current research, with the purpose of gathering background information. The second part is the core 35 items of the 5 measurement factors. The questionnaire was evaluated by five online teaching professionals from different regions, including Hong Kong, Macau, China, and Australia. Questionnaire items are reviewed and adjusted by identifying unclear content, misleading items, rephrasing, and rephrasing. The influencing factors and measurement items of the questionnaire regarding students' online learning readiness are summarized in Appendix 1. The last part is demographic questions, such as age, gender, education level, department of study, etc., to collect background information for students.[10]

\subsection{Learning context}

The learning environment includes lectures, the student's learning process, teaching experience, assignments or tests (Govender, 2009). In this study, participants came from higher education sectors in different disciplines, such as business schools, engineering schools, social sciences, and applied sciences. The faculty of each institute was selected at random. The standard online learning environment in this study has two learning situations: classroom setting and homework. Lecture setting is a forum for teachers to impart knowledge and content to students. In the lectures, we strive to simulate the traditional teaching and learning environment before it became popular by providing live lectures. Students are required to attend classes on time and to impart and supplement lessons in real time. Students can also ask questions orally or in writing in class. Assignment setting is an exercise or task that assesses a student's ability to understand at the required level in class. Assessment tasks can also be used for ongoing assessment of students. Solving problems in the assignment setting confirms the student's intention to understand the lecture (Mo \& Tang, 2017).[11]

\subsection{Validity test and analysis}

$$
\operatorname{HTMT}_{i j}=\frac{1}{K_{i} K_{j}} \sum_{g=1}^{K_{i}} \sum_{i=1}^{K_{j}} r_{i, j, j} / \sqrt{\frac{2}{K_{i}\left(K_{i}-1\right)} \sum_{g=1}^{K_{i}-1} \sum_{h=\xi+1}^{K_{i}} r_{i, j, j} \times \frac{2}{K_{j}\left(K_{j}-1\right)} \sum_{g=1}^{K_{j}-1} \sum_{h=\xi+1}^{K_{i}} r_{i, j, k}}
$$

The mean score and standard deviation $(\mathrm{O})$ of 35 measures of 5 factors were used to compare students' readiness for online broadcast learning. We used two tests to determine gender differences and educational level differences in students' readiness for online learning. An independent sample $\mathrm{t}$ test was used to determine gender statistical differences. Multivariate analysis of variance (MANOVA) was used to compare the differences of students' educational attainment among the five measurement factors. In both tests, the difference of $\mathrm{P}<0.05$ was statistically significant by $5 \%$. Finally, this study also attempts to investigate the influence of different factors on the learning readiness of different groups of students through multi-group analysis (MGA) of CFA. MGA is a comparison of different students, including male and female students and PG, UG and SD students.[12]

\section{RESULT}

\subsection{Validity test}

All the model fitting measurement statistics are in good agreement with the model fitting indexes. Therefore, we believe that this model has good reliability and validity. At the same time, the variance interpretation ratio proposed by Hair et al. (2011) was calculated to evaluate the predictive ability criteria of the structured model, to investigate its quality. According to the empirical rule proposed by Henseler et al. (2009), the explanatory variance of the potential dependent variables in the model to the total variance is calculated. The 
research results show that technology maturity and autonomous learning have moderate predictive ability, while the factors such as learner control, online communication self-efficacy and learning motivation have strong predictive ability.[13]

\subsection{Students' readiness for different genders}

In this study, a total of 383 men $(41.9 \%)$ and 530 women $(58.1 \%)$ participated in online learning.

To investigate differences in online learning readiness between male and female students, an independent sample t-test was used. According to the survey, women generally scored higher on average than men in all the factors affecting live online learning. But the difference between the two groups was not statistically significant.

\subsection{Students' readiness for different education level}

In this study, 323 (35.4\%)SD students, 372 (40.7\%)UG students and 218 (23.9\%)PG students participated. The readiness of the students for these five factors was measured. The results showed that the average scores of PG students on the five measurement factors were generally higher than those of UG and SD students, while there was no significant difference between UG students and SD students. There were significant differences in the degree of preparation for online real-time learning among students' education level $(\mathrm{F}=1.660, \quad \mathrm{P}=0.013<0.05)$. Wilks' Lambda and Hotelling's Trace differences in education levels are 6.18 and 6.23, respectively. According to MANOVA, the educational level of students is higher than that of students in technical preparation $(\mathrm{F}=4.80, \mathrm{P}=0.008<$ $0.01)$, learner control $(\mathrm{F}=6.76, \mathrm{P}=0.001<0.01)$, autonomous learning $(\mathrm{F}=4.89, \mathrm{P}=0.008<0.01)$ and student motivation $(\mathrm{F}=18.19, \mathrm{P}=0.000<0.01)$.

\subsection{Multi-group analysis}

The MGA also aims to address how different factors affect students' readiness for real-time online learning. In the analysis, complete models of PG, UG, and SD student groups were compared. The results showed that the factor load of PG group, UG group and SD group were 0.78 $0.97,0.82 \sim 0.98$ and $0.75 \sim 0.94$, respectively. This study finds that motivation, online communication and learner control are the main factors that affect students' online learning readiness. On the other hand, comparisons were made for men and women at all levels of education. The results showed that the factor load of male group was between 0.68 and 1.00, and that of female group was between 0.81 and 0.97 . The study found similar results for men and women. In addition to independent learning has little effect on male students, other factors have a greater impact on students' readiness for online learning.
Similar results were found in the PG, UG and SD groups.[14]

\section{DISCUSSION}

\subsection{Factors contributing to online learning readiness}

Use computer/Internet self-efficacy instead of technical self-efficacy. Since computer and Internet skills have matured and the latest technologies have developed rapidly in this generation, this study uses a technology self-efficacy model (Bigatel et al., 2012) to revise previous studies. In many papers, technology is one of the core factors in the adoption of online teaching and learning (Phan \& Dang, 2017; Yurdagil et al. 2014: Glenda (2016). We believe our model can effectively reflect students' readiness for online real-time learning.

\subsection{Difference between genders}

Our results show that there are significant differences between men and women in these five influencing factors. Girls are more motivated to learn because they are more interested in using communication and technology tools for learning (Unal, Alir, \& Soydal, 2014). Girls' better communication skills can also be explained by the fact that girls prefer to use written communication over boys, or that girls prefer written communication over oral communication. At the same time, on-site learning and coronavirus outbreaks may be the reasons for male students to participate more actively in online learning, thereby narrowing gender differences in motivation and communication readiness among students, among other contributing factors.[15]

\subsection{Difference between education levels}

Previous research has shown that there is little correlation between online learning readiness and educational level of degree study, particularly among SD, UG and PG students. In our study, there were significant differences in the readiness of students with different educational levels for online live learning. The results are consistent with the findings of Rasouli et al. (2016), that is, there are significant differences in the readiness of UG students, PG students and graduates in e-learning. Our results are consistent with Wojciechowski and Palmer's (2005) view that older students, especially those at master's level or above, are more successful in online courses. We believe that the academic performance of SD students is very important for them to continue to study UG after graduation. As a result, there was no significant difference in learning readiness compared to $\mathrm{UG}$ students. As can be seen from the results of this study, changes in teaching and learning caused by the coronavirus epidemic may have contributed to 
differences in student readiness, especially at higher education level.

\subsection{Implications for educators}

The results of the current study have several important implications for educators implementing realtime online learning in the future. According to the statistical analysis of this study, students' readiness for online real-time learning is determined by five core factors. Students' learning motivation and communication self-efficacy, especially boys, can learn from their peers more actively in the future. Educators can consider various strategies for enabling peer support for students, such as creating communities, encouraging teamwork, and using existing social networking tools to facilitate collaborative learning among students. On the other hand, more efforts can be made to increase their motivation for students with low educational levels to study online. Although PG students showed significant readiness on most of the measurement factors, there was no significant difference in online communication selfefficacy, suggesting that teacher-student communication and student-student interaction can promote questionand-answer sessions in order to develop better online communication habits and improve students' online realtime learning readiness.

\section{CONCLUSIONS}

The difference between male and female is not significant, but the scores of readiness between subdegree students, undergraduate students and postgraduate students are significantly different. PG students have higher motivation for learning than UG and SD students. PG students also have higher technology readiness, learner control, and self-directed learning ability than SD students. However, no significant difference was found for online communication self-efficacy.

The findings will be used for driving improvement of students in lower education level. Under COVID-19, this is the first attempt to implement online learning platform. It would be important to investigate further the degree of emotional changes in students learning during the COVID-19 pandemic. Further investigation can determine how variables such as institution and background influence their learning. To further improve the teaching practice and strategies of network teaching, provide evidence-based guidance for front-end teachers to continue to conduct network teaching in the future.

\section{REFERENCES}

[1] Ribeiro.R. (2020, April 14). How university faculty embraced the remote learning shift. EdTech Magazine. https://edtechmagazine.com/higher/artic le/2020/04/how-university-faculty-embracedremote-learning-shift [Google Scholar]
[2] Feldman,J.(n.d.). To Grade or Not to Grade?. https://filecabinetdublin.eschoolview.com/ 6D88CF03-93EE-4E59-B267-

B73AA2456ED7/ToGradeorNottoGradearticle.pdf [Google Scholar]

[3] Demirbilek, M. (2014). The 'digital natives' Debate: An Investigation of the digital Propensities of University students. Eurasia Journal of Mathematics, Science \& Technology Education , 10 (2), https://doi.org/10.12973/eurasia. 2014.1021a [Crossref], [Web of Science ®], [Google Scholar]

[4] Fishbane, L. , \& Tomer, A. (2020, March 20). As classes move online during COVID-19, what are disconnected students to do? Brookings. https://www.brookings.edu/blog/th e-avenue/2020/03/20/as-classes-move-onlineduring-covid-19-what-are-disconnected-studentsto-do/ [Google Scholar]

[5] Manfuso, L. G. (2020, April 15). How the remote learning pivot could shape Higher Ed IT. EdTech Magazine. https://edtechmagazine.com/higher/artic le/2020/04/how-remote-learning-pivot-couldshape-higher-ed-it [Google Scholar]

[6]

Iqbal, S. , Zang, X. , Zhu, Y. , Hussain, D. , Zhao, J ., Gulzar, M. M. , \& Rasheed, S. (2015, November 13-15). Towards moocs and their role in engineering education. 2015 7th International conference on information technology in medicine and education (ITME) (pp. 705-709). IEEE. https://doi.org/10.1109/ITME.2015.89 [Goo gle Scholar]

[7] Murphy, B. (2020, April 23). Medical school assessment during COVID-19: Shelf exams go remote. American Medical Association. https://www.ama-assn.org/residentsstudents/medical-school-life/medical-schoolassessment-during-covid-19-shelf-examsgo [Google Scholar]

[8] Boczkowska, K. , Bakalarski, P., Sviatoslav, M. , \& Leszczyński, P. (2018). The importance of elearning in professional improvement of emergency nurses . [Google Scholar]

[9]Eastern Mediterranean University . (2020). Visual Arts and Communication Design Department: EMU Visual Arts and Communication Design Department's Contribution to Health Workers. Retrieved April 21, 2020, from https://www.emu.edu.tr/en/news/news/emuvisual-arts-and-communication-design- 
departments-contribution-to-healthworkers/1206/pid/3393 [Google Scholar]

[10] Joosub, S. (2020, April 23). Vodacom helps to flatten the COVID-19 curve through technological innovation. https://www.vodafone.com/covid19/ne ws/vodacom-helps-to-flatten-covid-19-curvethrough-technological-innovation [Google Scholar]

[11]Ala-Mutka, K. , Punie, Y. , \& Redecker, C. (2008). Digital competence for lifelong learning (policy brief). European Communities. [Google Scholar]

[12] Han, F., \& Ellis, R. A. (2019). Identifying consistent patterns of quality learning discussions in blended learning. The Internet and Higher Education , 40 , 1219. https://doi.org/10.1016/j.iheduc.2018.09.002 [ Crossref], [Web of Science ${ }^{\circledR}$ ], [Google Scholar]

[13] Osterlind, S. J. (2002). Constructing test items: Multiple-choice, constructed-response, performance, and other formats (2nd Ed.). Kluwer Academic. [Google Scholar]

[14] WHO. (2020). Coronavirus disease (COVID-19) pandemic. World Health Organization. https://www.who.int/emergencies/dis eases/novel-coronavirus-2019 [Google Scholar]

[15] Shariman, T. P. N. T. , Razak, N. A. , \& Noor, N. F. M. (2012). Digital literacy competence for academic needs: An analysis of Malaysian students in three universities. Procedia-Social and Behavioral Sciences , 69 (1), 14891496. https://doi.org/10.1016/j.sbspro.2012.12.090 [Crossref], [Google Scholar] 